\title{
Self-directed learning with a modified team-based strategy: A quasi-experimental study
}

\author{
Huei-Lih Hwang ${ }^{1}$, Chin-Tang $\mathrm{Tu}^{2}$, Tian-Yuan Kuo*3 \\ ${ }^{1}$ National Tainan Junior College of Nursing, Taiwan \\ ${ }^{2}$ National Kaohsiung Normal University, Taiwan \\ ${ }^{3}$ Fooyin University, Taiwan
}

Received: December 27, 2020

Accepted: March 22, 2021

Online Published: August 4, 2021

DOI: $10.5430 /$ jnep.v11n12p38

URL: https://doi.org/10.5430/jnep.v11n12p38

\begin{abstract}
Background and objective: Physical assessment skills are not effectively put into practice for nursing students, requiring an improvement in pre-registration programs and planning more tailored training courses for them. More flexibility in teaching methods can thus contribute to self-directed learning. The purpose of this study is to identify the effects of team-based learning when combined with an online teaching platform on self-directed learning compared to inquiry-based learning for junior college nursing students.

Methods: In this quasi-experimental study, 103 students completely participated in the Self-directed Learning Instrument test before and after the course. Collected data were analysed using independent t-test and ANCOVA with the statistical package SPSS 21.0 for Windows. Qualitative focus group interviews were conducted after the survey with 14 participants.

Results: Compared to the control group, the adjusted mean post-test score for self-directed learning ability was significantly higher in the intervention group. Students also reported that they were quite engaged in completing assignments and team learning activities in classroom, specifically for the group test.

Conclusions: The modified team-based learning strategy was useful at engaging students to improve self-directed learning and to satisfy them. Educators are encouraged to integrate online response system technology into their classroom activities.
\end{abstract}

Key Words: Nursing students, Team-based learning, Self-directed learning

\section{INTRODUCTION}

Lifelong learning is necessary for nurses in the U.S. and required in order to maintain nursing education accreditation. ${ }^{[1,2]}$ Moreover, self-direction is one of the major characteristics of lifelong learning. ${ }^{[3]}$ The goal through self-directed learning (SDL) is to improve patient outcomes. SDL has significantly increased knowledge acquisition among postsecondary students through a quasi-experimental study. ${ }^{[4]} \mathrm{A}$ survey of 169 final-year nursing students, however, showed that they possessed a low level of $\mathrm{SDL}^{[5]}$ and suggested to enhance their tendency to consider learning as their responsibility rather than a commitment required by others.

Physical assessment, an important part of effective medical interventions, is integral to any nursing degree program and is recognized as required for competence. ${ }^{[6]}$ However, most nursing students are not adequately prepared to conduct physical assessments for patient. ${ }^{[7]}$ Researchers indicated that traditional teaching methods offer limited development of a student's background knowledge and competence in physical assessment ${ }^{[8]}$ and do not give students enough experience in

*Correspondence: Tian-Yuan Kuo; Email: sc038@fy.edu.tw; Address: 151 Jinxue Rd., Daliao Dist., Kaohsiung City 83102, Taiwan. 
practicing skills for physical assessments. ${ }^{[9]}$ Cantrell and Farer (2019) interviewed 220 undergraduate nursing students between 18 and 24 years old in traditional nursing classrooms. These students stated that they were physically present, but mentally distracted, were learning material for tests, but for not for practical use, and desired more from disengaged professors. ${ }^{[10]}$ Educators should therefore improve pre-registration programs and plan more specialized training courses.

\subsection{Teaching approaches}

Generation $\mathrm{Z}$ students who aged 11-17 and their native technology environment strongly influenced them in terms of communication and education. To achieve deeper and more effective learning that meets the needs of Generation $\mathrm{Z}$ students, a type of blended learning called flipped classrooms, which aim to increase student engagement and learning by having students read information at home and work on live problem-solving during class time, have been developed. ${ }^{[11]}$ Student-centred approaches have also been created in a variety forms, including learning activities such as team-based, problem-based, inquiry-based, and simulation-based that have been also adopted in academia to offer opportunities for students' hands-on learning instead of passive listening. ${ }^{[12]}$

Team-based learning (TBL), a form of flipped teaching and dialectic teaching grounded in constructivist learning theory, is an economical approach, because one instructor can work with many smaller groups, facilitating active learning and giving timely feedback to each other. ${ }^{[13]}$ To promote the success of a team, large classes are separated into smaller groups with as much diversity of knowledge and experience as possible. This gives each small group the greatest amount of possible resources to draw upon when problem-solving. ${ }^{[14]}$ Successful TBL develops classroom engagement, teamwork skills, core competencies (including communication, critical thinking, clinical skills, and self-leadership), and self-directed learning among nursing students ${ }^{[15-17]}$ and also stimulates long-term knowledge retention and knowledge-based performance. ${ }^{[13,18,19]}$

Pre-class learning in a flipped classroom plays a pivotal role in allowing the classroom to serve as an active learning environment where students can work through complex and real situations with the benefit of peer learning and instructor guidance. To encourage students to participate in critical discussions as they learn, inquiry-based learning (IBL) was proposed to improve their practical problem-solving skills. ${ }^{[20]}$ There are various levels of inquiry; ${ }^{[21]}$ guided inquiry, for example, involves the teacher providing questions to students, who then design their own procedures to search for answers and present results. Tamari and Ho (2019) found

Published by Sciedu Press that instructor-guided IBL approaches in biology courses work well and have positive impacts for college students in terms of remembering content and developing competencies in data analysis and critical thinking. ${ }^{[22]}$ In addition, scholars advocate for creating instructional approaches that combine elements of problem-based learning and TBL in order to optimize student learning. ${ }^{[23]}$

To take advantage of familiarity with technology among Generation Z, adopting digital presentations can additionally enhance students' interest and active learning. ${ }^{[24]}$ Several online student response systems (OSRS) have been developed and implemented in higher education worldwide to facilitate quality learning in courses such as English, computer architecture, nursing informatics, and even in continuing medical education. ${ }^{[25-28]}$ Smartphone-enabled OSRS enhances learning experiences through interactions between classmates. Educational researchers have provided solid evidence for the benefits of using response systems, including student engagement, classroom interaction, competency and learning outcomes, and useful feedback for teaching and learning. Many OSRS are available to instructors for free, such as Socrative, Formative, Kahoot, and Quizizz, among others. Zuvio is one type of OSRS adopted by many universities in Taiwan. It has three functional systems: grading, multimedia testing, and peer assessment for course evaluation. Zuvio can calculate and record personalised answers, which allow for both class discussion and specific student-instructor interactions.

Limited research has been conducted discussing the effects of adopting varied instructional approaches of SDL among junior nursing students. No study has explored the effects of adopting such interventions in nursing education on physical assessment. Can these interventions improve student engagement and achievement in order to establish more equitable course modules? This study uses both qualitative and quantitative research methods to explore the following issues: (1) what impact does course design have on students, (2) if varying instructional approaches can promote students' self-directed learning, (3) and whether related factors contribute to students' learning outcomes. Based on limited studies, we formulate these hypotheses: (1) students who attend the innovative teaching strategy gain satisfaction and classroom engagement, and (2) students have better ability of learning-thinking-expressing and self-directed learning in the intervention group versus the control group.

\section{METHOD}

\subsection{Design and participants}

This study applied a pre-test and post-test with randomized control group design. The aim was to compare the effect of 
the innovative teaching strategy on nursing students' learning performance between the test group (three-section innovative classroom activities first and one-section lecture) and the control group (one-section lecture and three IBL). The intervention was a set of innovative teaching strategies for a physical assessment course provided to students who were enrolled in a 5-year diploma nursing program in 2018 at one junior college. One faculty member who had eight years of experience in teaching physical assessment taught the three classes in the study and used the same course contents except for using different teaching strategies in the test groups.

$\mathrm{G}^{*}$ Power 3.1 was used to calculate the necessary sample size. For a covariance test with a significance level of $\alpha=$ .05 , medium effect size of $d=.25$, and statistical power of .80 , the minimum sample size for the total sample size was 128. One hundred and forty students enrolled in the course and were assigned randomly by computer to four classes. We choose three classes which one class was assigned to the control group, two classes were assigned to the test group. 41 out of 44 participants in the control group and 62 out of 68 participants in the intervention group completed the pre-test and post-test questionnaires. Finally, the response rates were $93 \%$ in the control group and $91 \%$ in the experimental group.

\subsection{Instruments}

Self-directed Learning Instrument (SDLI), developed to measure self-directed learning ability, consists of 20 items across four domains (learning motivation, planning and implementing, self-monitoring, and interpersonal communication) and has been validated by confirmatory factor analysis for showing a good fit of the model on Taiwan's nursing students. ${ }^{\text {[29] }}$ The value of Cronbach's alpha for the total scale was .916 and for the four domains were $.801, .861, .785$, and .765 , respectively. In the current study, the Cronbach's alpha was 95. The validity was tested by factor analysis, and SDLI explained $60.04 \%$ of the variation in self-directed learning.

\subsubsection{Ability of learning-thinking-expressing}

Based on the philosophy of flipped classroom, we developed a 7-item five-point Likert-type questionnaire named ability of learning-thinking-expressing for this study to evaluate learning effects for participating in the course activities. The items in this questionnaire include ability to search references, reading, discussing, synthesizing in writing, and verbal expression. In the current study, the Cronbach's alpha was .892. The validity was tested by factor analysis, and the 7 -item questionnaire explained $54.79 \%$ of the variation in learning-thinking-communication.

\subsubsection{Student satisfaction and classroom engagement}

To assess students' learning satisfaction from team-based learning activities, a 9-item Student Satisfaction scale developed by Mennenga (2012) was adopted. ${ }^{[30]}$ In the current study, the Cronbach's alpha was .826. The validity was tested by factor analysis, and the questionnaire was able to explain $58.13 \%$ of the variation in the team-based learning effect.

The 8-item, five-point Likert-type Classroom Engagement Survey $(\mathrm{CES})^{[31]}$ measuring the students' engagement during class was developed and tested on post-secondary education participants in Baylor University with adequate validity. Another study also supported the reliability of CES, with Cronbach's alpha values of .80 in a sample of nursing students. For the two subscales of learners' participation (5 items) and learners' enjoyment of class (3 items), Cronbach's alphas were 0.80 and 0.81 , respectively. ${ }^{[32]}$ In the current study, the Cronbach's alpha was .876 , and CES was able to explain $66.87 \%$ of the variation in the class engagement.

\subsubsection{Structure of innovative teaching module}

The interventions comprised a 9-hour three-week TBL intervention, named as the 'modified team-based strategy'. Each course was administered in one weekly 3-hour class for a period of four weeks. To address the learning objectives, the instructor designs the course into three repeating phases. The first phase involves a pre-class learning assignment where the students need to search for the answers by themselves for the guided inquiry and read the study material (physical assessment films and PowerPoint slides) provided by the instructor one week ahead. To stimulate peer collaborative learning for the course, students form a team of four to five members with relative evenness in academic achievement between teams.

The second phase focuses on readiness assurance and has four steps. Initially, the individual readiness assurance test (IRAT) on ZUVIO shows the score and answer immediately after completion of the answers. The group readiness assurance test (GRAT), by using a scratch-off answer sheet, allows group members to reach a consensus on the answer during team discussion and to correct each decision during scratching. The scratch-off answer sheet contains the correct answer for each question. The focus of the two tests is on recall of the factual material. Next, students are allowed to appeal in speech any questions related to answers that they do not feel are fair. As a final step, the instructor debriefs and addresses any misconceptions and new information around the content.

The third phase of the process, called application activity, is when the groups make a solution for a multiple-choice question, and all groups simultaneously report their solution. 
The problems related to assessment for dyspnea, abdomen pain, and chest pain have many solutions that allow for debate of the correct answer. To promote student interests in and enthusiasm for the team competition, we drew a conch shell on board as scoring for each team.

\subsection{Ethical consideration}

An exploratory mixed methods design, approved by the $\mathrm{Na}-$ tional Cheng Kung University Human Research Ethics Committee (107-035), was applied to evaluate the effectiveness of a practice-based teaching intervention from multiple perspectives. The intervention group of students engaged in classroom activities three time by using IBL, TBL combined OSRS, and one-time lecture format activity on physical assessment. The control group of students were mainly involved in oral report pre-class learning assignments with the teacher's summary.

\subsection{Data analysis}

Descriptive statistics were calculated, including means and standard deviation for dependent variables. Homogeneity tests were conducted before the intervention using the independent $t$ test for age, past grade point average, and selfdirected learning level. Five separate univariate analyses of covariance (ANCOVA) with the pre-test and past grade point average as covariates were applied to compare the difference between the two course designs. Statistical analysis was conducted using IBM SPSS statistics 21.0.
The qualitative aspect of the study was augmented by triangulating students' qualitative data with a focus group discussion ( $\mathrm{n}=16)$ and instructor reflection. Focus group data were audio-taped and then transcribed verbatim by an assistant. A manual thematic analysis was undertaken by the author and one colleague independently. To promote trustworthiness and credibility, the categories generated were discussed prior to integrating them into consensually-agreed themes. To alleviate bias and potential conflict of interest associated with the researcher teaching the class, data were collected and analysed by a colleague. Transcripts and answer sheets were analysed by qualitative content analysis. ${ }^{[33]}$

\section{Results}

This article presents an evaluation of innovative strategies for students in a capstone course. It reports statistical analysis and emerging themes from student perspectives on their course experiences.

\subsection{Demographic characteristics}

The participants ranged in age from 19 to 21 years, and $90.2 \%$ were female. The mean age of the participants was 19.19 years $(\mathrm{SD}=.475)$, and the mean past grade point average was $82.86(\mathrm{SD}=2.698)$. As shown in Table 1 , only pre-test scores for SDL significantly differ between groups $(\mathrm{F}=5.893, p=.017)$, and thus we adopt ANCOVA to control the pre-test score in the next analysis.

Table 1. Comparison of demographic and pretest data between two groups of residents $(n=112)$

\begin{tabular}{|c|c|c|c|c|}
\hline \multirow{2}{*}{ Variables } & EG $(n=68)$ & $C G(n=44)$ & \multirow{2}{*}{ F test or $\chi^{2}$} & \multirow{2}{*}{$p$} \\
\hline & $\mathrm{M} \pm \mathrm{SD}$ or number & $\mathrm{M} \pm \mathrm{SD}$ or number & & \\
\hline Age (yrs) & $19.25 \pm 0.505$ & $19.16 \pm 0.428$ & 1.07 & .600 \\
\hline Gender (female) & $89.7 \%$ & $90.9 \%$ & .173 & .835 \\
\hline Past grade point average & $82.97 \pm 2.5$ & $82.71 \pm 2.99$ & 1.394 & .627 \\
\hline SDL & $68.10 \pm 7.35$ & $63.83 \pm 10.49$ & 5.893 & .017 \\
\hline
\end{tabular}

Note. SDL: Self-directed learning ability, EG: intervention group, CG: control group.

\subsection{Effect of intervention on students' SDL (self- directed learning) ability}

SDL and other subscales were compared individually between the intervention group and the control group before and after the intervention for the junior college students. Five separate univariate analyses of covariance (ANCOVA) were performed. Before performing ANCOVA, the interactive effects of covariate and groups on the predictions of SDL and four subscales were evaluated. The analysis of SDL and all subscales revealed no significant interacting effects among groups $(\mathrm{F}=.2312 .529, p=.115 .632)$. Compared to the control group, the adjusted mean post-test scores Published by Sciedu Press for SDL were significantly higher in the intervention group. Furthermore, the adjusted mean scores for three subscales (Motivation, Self-monitoring, and Communication) were significantly higher in the intervention group, except that the subscale of "Planning and implementing" $(\mathrm{F}=2.515, p=$ .116) did not significantly differ (see Table 2).

\subsection{Other learning effects after modified team-based learning}

After the innovative teaching strategy, student engagement in classroom and satisfaction on team-based learning which is the ability of learning-thinking-expressing was evaluated and 
perceived to be above medium for the intervention group (see Table 3). Scores in perceive d learning-thinking-expressing significantly increased $(t=10.26, p<.001)$ by comparing the pre-survey and post-survey in the intervention group $(22.89$, $3.41 ; 27.71,3.16)$. The level of student engagement during class time was highest in the abdomen unit, which was the easiest part of the course. Participants also claimed that they put efforts on course-related activities $(3.99, .43)$ and were satisfied with team-based learning $(3.74, .43)$.

Table 2. Effects of the innovated approach for teaching physical assessment on posttest variables $(\mathrm{n}=103)$

\begin{tabular}{lllllllllll}
\hline Sources & EG & CG & \multirow{2}{*}{ SS } & df & MS & F-value & p & $\boldsymbol{\eta}^{2}$ & OP & $\begin{array}{l}\text { Post-hoc } \\
\text { test }\end{array}$ \\
\hline SDL & $\mathbf{M} \pm \mathbf{S E}$ & $\mathbf{M} \pm \mathbf{S E}$ & & & & & & & \\
Motivation & $23.78 \pm 1.14$ & $74.54 \pm 1.41$ & 420.16 & 1 & 420.16 & $5.279^{*}$ & .024 & .05 & .624 & EG $>$ CG \\
PI & $23.03 \pm 0.37$ & $22.10 \pm .44$ & 21.27 & 1 & 21.271 & 2.515 & .116 & .024 & .349 & EG $>$ CG \\
Self-monitoring & $15.82 \pm 0.22$ & $14.62 \pm 0.27$ & 36.24 & 1 & 36.24 & $11.25^{* *}$ & .001 & .098 & .914 & EG $>$ CG \\
Communication & $16.07 \pm 0.25$ & $14.83 \pm 0.29$ & 37.74 & 1 & 37.74 & $9.916^{* *}$ & .002 & .088 & .877 & EG $>$ CG \\
\hline
\end{tabular}

${ }^{*} p<.05,{ }^{* *} p<.01$, EG: Intervention group, CG: Control Group; SDL: Self-directed learning ability, PI: Planning and implementing, IC: Interpersonal communication; M: Adjusted Mean, SE: Standard Error, SS: Sum of Squares, MS: Mean Square, $\eta^{2}$ : eta squared, OP: Observed Power.

Table 3. Other learning effects

\begin{tabular}{lcll}
\hline Variables & $\mathbf{n}$ & $\begin{array}{l}\mathbf{M} \pm \mathbf{S E} \\
\text { Pre-test }\end{array}$ & $\begin{array}{l}\mathbf{M} \pm \mathbf{S E} \\
\text { Post-test }\end{array}$ \\
\hline Learn-think-express (7 items) & 62 & & $27.71 \pm 3.16$ \\
Classroom Engagement (1 5) & & & \\
Abdomen & 66 & & $4.20 \pm 0.45$ \\
Respiratory & 35 & & $3.85 \pm 0.48$ \\
Neuron & 66 & $22.89 \pm 3.41$ & $3.88 \pm 0.58$ \\
Team OSCE & 27 & & $3.82 \pm 0.61$ \\
Accountability (1 5) & 62 & & $3.99 \pm 0.43$ \\
Satisfaction on TBL (1 5) & 62 & & $3.74 \pm 0.43$ \\
\hline Note. OSCE: objective structure clinic examine, TBL: team-based learning
\end{tabular}

\subsection{Experience and suggestions of participants in this course}

Qualitative thematic analysis of the focus group data identified two predominant themes, with each one containing sub-themes concerning the sixteen participants' experience and suggestions for the course design. Their replies were mainly classified as 'Deeper learning', 'Motivated', 'Contributors', and 'Expecting'.

In their interviews, the focus group was most likely to use terms like reviewing knowledge, as well as comprehensive and impressive physical assessment skills. They were also likely to use terms like motivated to learn, think, and speak. Selected quotations from the interviews are presented below to illustrate these themes.

'This course facilitates our ability to think and express ourselves. There was a pre-class assignment containing 5 to 8 inquiries, which provided student direction to search and discuss the best answers with our team ahead of time....Everyone has an opportunity to report in front of the class. This obviously helps my verbal expression abilities.'

'During class, there were chances for adding to the team score by replying to the teacher's inquiry with immediate release group scoring in class. In other classes, raising your hand to give answers or share opinions in front of class for adding to your score on individual performance is not welcome. Instead, to fight for team honour we are more eager to discuss answers within our team and raise our hands to express our answers.'

The participant experiences of the innovated approach were overall positive in terms of skills and knowledge acquisition and retention. However, there were comments related to the inquiry-based learning and course introduction.

'There was confusion after student presentations. We expected our teacher not only to give comments, but also to summarize and emphasize the key points to be memorized for students. In the future, more case discussion and course description are suggested to enhance student learning.'

'We choose this course expecting to review what we have learned to prepare for senior college entrance exams.... after searching for pre-class inquiries, we did not have time to review books for related diseases... I suggest fewer inquires for answer and test items in this class be related to pre-class inquiries.'

\section{DiscuSSION}

The modified TBL combined with OSRS verified that students did perceive higher SDL after participating in 
the course activities, especially in the Motivation, Selfmonitoring, and Communication domains. This curriculum was different from the curriculum of Liou et al. (2013), which was implemented over a full semester, thus enabling substantial discussions on campus. The study results still indicated substantial impact on the development of self-directive learning through the 9-hour course activities in three weeks for the Integration of Clinical Practice course in physical assessment. ${ }^{[14]}$ This is possible, because the physical assessment course is not new for the participants, while the students in the nursing research course of the Liou et al. (2013) study were experiencing the material for the first time. ${ }^{[16]}$

We created innovative strategies allowing for higher-order cognition. Participants perceived that the course design helped with their clinical nursing practicum and future license examination. Moreover, participants recognized that inquiries often have more than one answer depending on the context and realized that knowledge may not be fixed and permanent and is instead open to questioning, thus enhancing SDL further. However, solving problems in IBL is a complicated learning process, whereas traditional learning is simpler. In the focus group interviews, we identified that some learners experienced a sense of frustration at being involved in the learning process and expected teachers to organize answers for them. Similar to what Hamilton et al. (2012) discovered after focus group evaluations, some participants initially felt uncertain of IBL as a learning method. ${ }^{[34]}$ Over the months, they soon gained confidence that IBL was a valuable strategy to enhance learning. Students need to conquer their reliance on traditional classroom lectures and be willing to accept self-learning responsibility, which comes with a flipped classroom. ${ }^{[35]}$

This course adopted TBL and IBL activities corresponding to Dolmans et al. (2015) who contended that TBL could benefit from IBL when students are encouraged to generate their own answers. ${ }^{[23]}$ The characteristics of TBL might increase students' motivation and promote individual accountability by means of structured peer evaluation and inter-team discussions that allow for prior knowledge to expand over an entire class. Similar to other findings, ${ }^{[36]}$ IBL and TBL reinforce students' learning motivation. Student motivation is the principal element of a successful learning process. ${ }^{[8]}$ Motivating students to accept responsibility for their learning facilitates educational activities and promotes SDL.

For a capstone course in the final year of nursing college programs, simply reviewing concepts or skills for the Integration of Clinical Practice will not equip pre-registration students to meet their clinical challenge. Instead of pre-class learning assignments in TBL covering the lower levels of cognition

Published by Sciedu Press (recall and realize), we adopted IBL, which involved higher levels of cognition (application, analysis, and synthesis), interaction, and collaborative learning. ${ }^{[8]}$ Before class, students in each team were required to review the questions that the teacher proposed and then to search for, analyse, synthesise the data to answer the questions correctly. Despite the above benefits, TBL and IBL were unfamiliar learning and teaching strategies for participants in this study. Scholars stated that good teaching is able to use strategies to make learning easier and to tailor them to the different learning styles of students. ${ }^{[37]}$ These responses echo the findings that some participants felt overloaded and suggested fewer questions for pre-class assignments and more achievement on IRAT.

While improvements in student learning increased with the use of such approaches due not only to varied teaching methods, factors such as technology and teachers' attitudes may also have been beneficial. As previously stated, the use of OSRS technology, specifically Zuvio, in a TBL classroom maintains students' engagement and active learning attitudes. ${ }^{[38]}$ As Zuvio was new for participants, they did not mention that Zuvio was difficult to use. This is consistent with the familiarity of Generation Z students with technology. From the interview findings, using OSRS for simultaneous choice reporting in both TBL application activities and individual readiness tests within the classroom is accepted by students and also facilitates their active learning and retention of physical assessment knowledge and skills.

\subsection{Limitation}

The innovated teaching approach was undertaken for only 9 hours over three weeks with pre-test and post-test designs. We are unable to infer the long-term effect on SDL. This study focused just on comparing two types of approaches, and so we cannot deny the learning effects of IBL. We also note that participants came from two focus groups, and so their experiences might have been different. To translate this educational innovation into practice, future teaching might benefit from having a clearer explanation before class starts, including acknowledgments of the challenges of this new type of learning and providing support for students throughout the process.

\subsection{Implication}

The innovated teaching strategy for the Integration of Clinical Practice course was effective in SDL and actively engaged nursing students in pre-class and in-class activities. The current work also raised the opportunity to improve educator performance in the application of this innovated teaching strategy. Further study can adopt a mini-lecture for explaining the purpose and expectations of the activity before the 
first day of class, to support students in class activities, to debrief pre-class inquiries, and to solicit and act upon student feedback about the activities so as to promote the efficacy of this teaching strategy. Overall, the findings from the survey and interview are encouraging, however, further evaluation must cover learners' knowledge, expected outcomes of adopted learning methods, and follow-up evaluation of students' SDL to ensure that the success of this strategy can continue to develop as an established feature.

\section{Conclusion}

This study shows that SDL significantly increased from the innovative teaching and learning strategy in a capstone course. To promote SDL, nursing students should be prepared and encouraged to actively engage in educational ac- tivities. Recurring themes did emerge from the focus group, such as 'Deeper learning' and 'Motivated', which highlighted areas that warrant actions from both students and teachers to ensure optimal learning. From the formative evaluation aspect, indicators such as student classroom engagement and satisfaction did meet the TBL active learning environment. The beneficial effect of the innovative teaching approach was also reflected in the survey, where students maintained a significantly higher level of performance in learning-thinkingexpressing from pre-test to post-test. The modified TBL combined with OSRS does offer students a more active learning environment where they have the opportunity to engage more extensively with both the instructor and classmates.

\section{Conflicts of Interest Disclosure}

The authors declare that there is no conflict of interest.

\section{REFERENCES}

[1] TNAC, Taiwan Nursing Accreditation Council: Accreditation criteria manual. Taipei: Higher Education Evaluation \& Accreditation Council of Taiwan; 2009.

[2] NLN. Academic progression in nursing education: A living document from the National League for Nursing. National League for Nursing; [cited 2021 Feb 7]. 2011 Jan. Available from: http://www.nln. org/docs/default-source/about/nln-vision-series-\% 28positionstatements $\% 29 /$ nlnvision_1.pdf?sfvrsn=4 https://doi.org/10.1046/j.1365-2648.2003.02673.x

[3] O'Shea E. Self-directed Learning in Nurse Education: A review of the literature. J Adv Nurs. 2003; 43(1): 62-70.

[4] Mohammed Ahmed WA, Yousef Alostaz ZM, Al-Lateef Sammouri GA. Effect of Self-Directed Learning on Knowledge Acquisition of Undergraduate Nursing Students in Albaha University, Saudi Arabia. AIMS Medical Science. 2016; 3(3): 237-247. https://doi.org/10.3934/medsci.2016.3.237

[5] Kaur M, Kaur N. Assessment of self-directed learning among nursing students. Baba Farid University Nursing Journal. 2014; 7(2): 46-54.

[6] Giddens J. A Survey of physical assessment techniques performed by RNs: Lessons for nursing education. J Nurs Educ. 2007; 46(2): 83-87. https://doi.org/10.3928/01484834-20070201-09

[7] Rylance R, Daye S. Do third-year mental health nursing students feel prepared to assess physical health? Ment Health Pract. 2017; 20(10): 26-30. https ://doi .org/10.7748/mhp. 2017.e1147

[8] Khalaf BK. Traditional and Inquiry-Based Learning Pedagogy: A Systematic Critical Review. International Journal of Instruction. 2018; 11(4): 545-564. https://doi.org/10.12973/iji.2018.1143 $4 \mathrm{a}$

[9] Wearn A, Bhoopatkar H, Mathew T, et al. Exploration of the attitudes of nursing students to peer physical examination and physical examination of patients. Nurse Educ Today. 2013; 33(8): 884-888. https://doi.org/10.1016/j.nedt.2012.08.012

[10] Cantrell MA, Farer D. Millennial Nursing Students' Experiences in a Traditional Classroom Setting. J Nurs Educ. 2019; 58(1): 27-32. https://doi.org/10.3928/01484834-20190103-05
[11] Europass Teacher Academy. Flipped classroom. [cited 2021 Feb 8]. Available from: https://www.teacheracademy.eu/course/f lipped-classroom/

[12] Mascolo M. Beyond Student-Centered and Teacher-Centered Pedagogy: Teaching and Learning as Guided Participation. Pedagogy and the Human Sciences. 2009; 1: 3-27. https : //www.researchgate .net/publication/228694201

[13] Hrynchak P, Batty H. The educational theory basis of team-based learning. Medical Teacher. 2012; 34(10): 796-801. https://doi. org/10.3109/0142159X . 2012.687120

[14] Michaelsen L, Parmelee D, McMahon K, et al. Team-based learning for health professions education: A guide to using small groups to improving learning. Virginia: Stylus Publishing; 2007. 9-31 p.

[15] Lee KE. Effects of Team-Based Learning on the Core Competencies of Nursing Students: A Quasi-Experimental Study. J Nurs Res. 2018; 26(2): 88-96. https://doi.org/10.1097/jnr.000000000000 0259

[16] Liou S, Cheng C, Tsai H, et al. Innovative Strategies for Teaching Nursing Research in Taiwan. Nurs Res. 2013; 62(5): 335-343. https ://doi.org/10.1097/NNR.0b013e31829fd827

[17] Roh YS, Lee SJ, Choi D. Learner Perception, Expected Competence, and Satisfaction of Team-Based Learning in Korean Nursing Students. Nurs Educ Perspect. 2015; 36(2): 118-120. https : //doi.org/10.5480/13-1200

[18] Cevik AA, ElZubeir M, Abu-Zidan FM, et al. Team-based learning improves knowledge and retention in an emergency medicine clerkship. Int J Emerg Med. 2019; 12(1): 1-1. https ://doi .org/10.1 $186 /$ s 12245-019-0222-2

[19] Lein DH, Lowman JD, Eidson CA, et al. Evaluation of teambased learning in a doctor of physical therapy curriculum in the United States. J Educ Eval Health Prof. 2017; 14: 1-5. https://doi.org/10.3352/jeehp.2017.14.3

[20] National Research Council. Inquiry and the national science education standards: A guide for teaching and learning. Washington, DC: National Academies Press; 1996. 9-13p. Available from: https : //www.nsf .gov/pubs/2000/nsf99148/pdf/ch_2.pdf

[21] NIH. Doing Science: The Process of Science Inquiry. National Institute for Health; [cited 2021 Feb]. 
https://science.education.nih.gov/supplements/webv ersions/processinquiry/intro/getting-started.html

[22] Tamari F, Ho IS. Guided Inquiry-Based Activities Positively Impact Learning in Community College Courses. J Coll Sci Teach. 2019; 48(4): 12-21.

[23] Dolmans D, Michaelsen L, van Merriënboer J, et al. Should we choose between problem-based learning and team-based learning? No, combine the best of both worlds! Med Teach. 2015; 37(4): 354359. https : //doi .org/10.3109/0142159X.2014.948828

[24] Hermanns M, Post JL, Deal B. Faculty experience of flipping the classroom: Lessons learned. J Nurs Educ Pract. 2015; 5(10): 79-85. https://doi.org/10.5430/jnep.v5n10p79

[25] Awedh M, Mueen A, Zafar B, et al. Using Socrative and Smartphones for the Support of Collaborative learning. Int J Integ Tech Educ. 2014; 3(4):17-24. https://doi.org/10.5121/ijite.2014.3402

[26] Su CF, Lin LW, Hung TY, et al. An Evaluation of the Use of Student Response Systems in Teaching Diagnostic Reasoning for Physicians. J Acute Med. 2018; 8(2), 60-65.

[27] Wang B. Applying PBL and Zuvio to Enhance English Learning Motivation. Int J Cyber Soci Educ. 2016; 9(1): 1-15. https: //doi.org/10.7903/ijcse.1433

[28] Wang W, Ran S, Huang L, et al. Student Perceptions of Classic and Game-Based Online Student Response Systems. Nurse Educ. 2019 Jul/Aug; 44(4): E6-E9. https ://doi.org/10.1097/NNE. 0000 000000000591

[29] Cheng SF, Kuo CL, Lin KC, et al. Development and preliminary testing of a self-rating instrument to measure self-directed learning ability of nursing students. Int J Nurs Stud. 2010; 47(6): 1152-1158. https://doi.org/10.1016/j.ijnurstu.2010.02.002
[30] Mennenga HA. Development and psychometric testing of the TeamBased Learning Student Assessment Instrument. Nurse Educ. 2012; 37(4): 168-172. https://doi.org/10.1097/NNE.0b013e3182 $5 \mathrm{a} 87 \mathrm{cc}$

[31] CES, Classroom Engagement Survey. Team learning in medical education workshop handbook. Houston, Texas: Baylor College of Medicine; 2001 Aug.

[32] Clark MC, Nguyen HT, Bray C, et al. Team-Based Learning in an Undergraduate Nursing Course. J Nurs Educ. 2008; 47(3): 111-117. https://doi.org/10.3928/01484834-20080301-02

[33] Graneheim UH, Lundman B. Qualitative content analysis in nursing research: concepts, procedures and measures to achieve trustworthiness. Nurse Educ Today. 2004; 24(2): 105-112. https: //doi.org/10.1016/j.nedt.2003.10.001

[34] Hamilton C, Yearley C, Boyle S. Evaluating enquiry-based learning in a new pre-registration programme. Br J Midwifery. 2012; 20(2): 129-134. https://doi.org/10.12968/bjom. 2012.20.2.129

[35] Findlay-Thompson S, Mombourquette P. Evaluation of a flipped classroom in an undergraduate business course. Bus Educ Accred. 2014; 6(1): 63-70.

[36] Tsai H, Wang F, Lee C, et al. The implementation of integrative case study in team-based learning reinforces student motivation in laboratory medicine. Clinica Chimica Acta. 2019; 493: S315-S316. https ://doi.org/10.1016/j.cca.2019.03.650

[37] Brown PC, Roediger HL, McDaniel MA. Make it stick: The science of successful learning. Cambridge, MA, US: Belknap Press of Harvard University Press; 2014. 21 p.

[38] Imazeki J. Bring your own device: Turning cell phones into forces for good. J Econ Educ. 2014; 45: 240-250. https : //doi .org/10 $.1080 / 00220485.2014 .917898$ 